\title{
PERBEDAAN TINGKAT KEPUASAN PASIEN NON JKN DENGAN JKN TERHADAP PELAYANAN POLIKLINIK GIGI DI FASKES TINGKAT I
}

\author{
Titin Clarita Siagian¹, Suci Erawati² \\ FAKULTAS KEDOKTERAN GIGI, UNIVERSITAS PRIMA INDONESIA, MEDAN, \\ INDONESIA \\ e-mail :titincsgn@gmail.com
}

DOI : https://doi.org/10.35451/jkf.v2i2.404

\begin{abstract}
The public health center as one of the public service institutions that is influenced by the development of health science, technological advancements and the socio-economic life of the community must be able to improve quality services and satisfy customers. The purpose of this study was to determine differences in the level of satisfaction of non JKN and JKN patients with dental polyclinic services at Health Center I Health Center Amplas City Medan. This research method is inductive comparative with cross sectional approach. The population is to use the average registered patient visits registered at 15,249 patients, the way of taking samples with proportional sampling of 100 respondents. The statistical test uses the Mann-Whitney $U$ Test with the help of a statistical program on the computer. The results showed that there were differences in the level of satisfaction of non JKN patients with the level of JKN patient satisfaction in Amplas City Health Center Medan ( $p$ value $=0,000$ ).
\end{abstract}

Keywords: Satisfaction, Patient JKN and Non JKN, Qualityof Service.

\section{Pendahuluan}

Jaminan Kesehatan Nasional (JKN) diselenggarakan oleh Badan Penyelenggara Jaminan Sosial (BPJS) kesehatan yang dimulai 1 Januari 2014.Program tersebut merupakan bagian dari Sistem Jaminan Sosial Nasional (SJSN) yang bersifat wajib berdasarkan Undang-Undang Nomor 40 Tahun 2004.Tujuannya adalah agar penduduk Indonesia terlindungi dalam sistem asuransi sehingga mengurangi risiko masyarakat menanggung biaya kesehatan dalam jumlah yang sulit diprediksi dan kadang-kadang memerlukan biaya yang besar. Peserta
Jaminan Kesehatan Nasional adalah setiap orang artinya diwajibkan untuk seluruh masyarakat Indonesia, termasuk orang asing yang bekerja paling singkat 6 (enam) bulan di Indonesia dan telah membayar iuran atau dibayarkan oleh pemerintah (Kemenkes, 2013).

Masyarakat yang telah terdaftar dalam program Jaminan Kesehatan Nasional (JKN) akan mendapatkan dua jenis pelayanan yaitu pelayanan kesehatan (manfaat medis) dan pelayanan non kesehatan (non medis). Misalnya pemberi pelayanan kesehatan 
adalah seluruh fasilitas layanan kesehatan primer dan rujukan yang bekerja sama dengan BPJS (Permenkes No. 28, 2014). Manfaat pelayanan dalam bidang kesehatan gigi dan mulut yang ditawarkan oleh BPJS diantaranya yaitu, konsultasi, pencabutan gigi sulung dan permanen, tumpatan dengan Resin Komposit dan Semen Ionomer Kaca, Pulp Capping (proteksi pulpa), kegawatdaruratan Oro-dental, Skeling atau pembersihan karang gigi, premedikasi atau pemberian obat dan protesa gigi. Perawatan skeling (pembersihan karang gigi) dibatasi satu kali per tahun, dan protesa gigi/ gigi tiruan yang lengkap maupun sebagian dengan ketentuan yang diatur tersendiri (Dewanto \& Lestari, 2014).

BPJS Kesehatan dalam melakukan kerjasama dengan fasilitas kesehatan harus mempertimbangkan kecukupan jumlah fasilitas kesehatan dengan jumlah peserta yang harus dilayani, dalam pemilihan fasilitas kesehatan BPJS Kesehatan melakukan seleksi menurut kriteria teknis, meliputi sumber daya manusia, kelengkapan sarana dan prasarana, lingkup pelayanan dan komitmen pelayanan (Permenkes No. 71, 2013). Pelayanan kesehatan dimulai dari fasilitas kesehatan tingkat pertama, fasilitas layanan kesehatan primer atau fasilitas kesehatan tingkat pertama diantaranya yaitu puskesmas.Puskesmas selalu berupaya agar perorangan, keluarga dan masyarakat memiliki kesadaran, kemauan untuk hidup sehat, berperan aktif dalam memperjuangkan kepentingan kesehatan termasuk pembiayaannya serta ikut dalam pelaksanaan program kesehatan.Pelayanan kesehatan dimulai dari fasilitas kesehatan tingkat pertama, fasilitas layanan kesehatan primer atau fasilitas kesehatan tingkat pertama diantaranya yaitu puskesmas.Puskesmas selalu berupaya agar perorangan, keluarga dan masyarakat memiliki kesadaran, kemauan untuk hidup sehat, berperan aktif dalam memperjuangkan kepentingan kesehatan termasuk pembiayaannya serta ikut dalam pelaksanaan program kesehatan. Puskesmas sebagai tulang punggung pelayanan kesehatan, oleh karena itu harus berusaha melakukan kendali mutu dan kendali biaya sesuai persyaratan kerja sama dalam sistem Jaminan Kesehatan Nasional (Taher, 2013).

Pelayanan kesehatan mengacu
pada konsep "managed care"
keterpaduan antara pelayanan
kesehatan yang bermutu dan pembiayaan yang terkendali. Kualitas pelayanan kesehatan adalah pelayanan kesehatan yang dapat memuaskan setiap pengguna jasa pelayanan kesehatan yang sesuai dengan tingkat kepuasan rata-rata penduduk dan penyelenggaraannya sesuai dengan standar dan kode etika profesi.Puas yang dimaksud yaitu perasaan masyarakat setelah membandingkan hasil yang dirasakan dengan harapannya.Tingkat kepuasan pelanggan sangat tergantung pada kualitas suatu produk barang atau jasa. Sifatnya subjektif, sesuai dengan jawaban responden menurut apa yang dirasakan. Pengukuran tingkat kepuasan pasien harus menjadi kegiatan yang tidak dapat dipisahkan dari pengukuran kualitas layanan kesehatan.Kurangnya sosialisasi dari pemerintah kepada masyarakat (Hani, 2015).

Hubungan kepercayaan pelayanan kesehatan JKN dengan status kepesertaan program JKN meliputi bagaimana harapan positif terhadap pelayanan kesehatan JKN dapat terpenuhi dengan baik sehingga dapat mempengaruhi status kepesertaan responden dalam program JKN. Hasil 
penelitian diperoleh bahwa lebih banyak responden yang memiliki kepercayaan terhadap pelayanan kesehatan JKN dibandingkan dengan responden yang tidak percaya.Sebagian besar percaya jika JKN adalah program yang baik dan mampu membantu masyarakat untuk memenuhi kebutuhan kesehatan.Namun, masih terdapat kekurangan yang terjadi di lapangan yang membuat masyarakat memiliki kepercayaan yang rendah terhadap pelayanan kesehatan JKN.

Adanya pengalaman buruk yang dirasakan ketika memanfaatkan pelayanan kesehatan, membuat responden beranggapan bahwa fasilitas kesehatan tidak dapat melayani dengan baik dan tidak memenuhi harapan responden.Menurut 49\% responden terlihat adanya perlakuan yang berbeda antara pasien yang menggunakan jaminan kesehatan dan pasien tanpa jaminan kesehatan.Hal tersebut membuat masyarakat menjadi tidak sepenuhnya percaya dengan pelayanan kesehatan, 35\% responden menyatakan obat yang diberikan adalah obat yang standar atau obat generik.

Berdasarkan hasil uji Koefisien korelasi Phi diperoleh bahwa tidak ada hubungan kepercayaan mengenai pelayanan kesehatan JKN dengan kepesertaan program JKN. Tidak adanya hubungan ini dikarenakan besarnya ekspektasi atau harapan responden terhadap pelayanan kesehatan JKN, dimana ekspektasi tersebut tidak mampu dipenuhi oleh pemberi jasa pelayanan kesehatan.

Ditemukan beberapa masalah berdasarkan Rakerkesnas 2015 yang dapat mempengaruhi tingkat kepuasan pasien di era JKN diantaranya yaitu terbatasnya jumlah, penyebaran dan kualitas tenaga kesehatan termasuk dokter gigi yang diperlukan untuk melaksanakan pelayanan kesehatan primer, keterbatasannya sarana prasarana dan alat kesehatan untuk mendukung pelayanan kesehatan, belum ada alat yang digunakan dalam kegiatan untuk proses peningkatan kualitas pelayanan kesehatan Masyarakat juga mengeluhkan mengenai prosedur JKN yang terlalu rumit dan bertele-tele dan harus melalui sistem rujukan yang berjenjang. Sebagian besar dikarenakan kurang pahamnya masyarakat tentang program JKN ini, kurangnya sosialisasi dari pemerintah kepada masyarakat.Keluhan terhadap lingkungan puskesmas yang kurang bersih, jadwal buka pendaftaran pasien tidak konsisten, terlalu lama antri serta dokter yang terburu-buru dalam melakukan pemeriksaan (Jalimun, Widjanarko, \& Peitojo, 2014).

Pada penelitian ini, responden yang merasa puas terhadap aspek struktur pelayanan adalah sebanyak 92,8\%. Elemen-elemen yang dinilai pada aspek struktur pelayanan adalah fasilitas dan Sumber Daya Manusia. Dari data hasil penelitian yang diperoleh, diketahui bahwa persentase kepuasan pasien pada variabel Fasilitas adalah sebesar $94,8 \%$. Berdasarkan observasi yang dilakukan peneliti selama berada di Puskesmas, pasien cenderung puas karena keadaan ruang tunggu serta Poliklinik Gigi terbilang bersih, rapi dan ditunjang dengan berbagai fasilitas seperti AC (air conditioner) di ruang tunggu pasien.Fasilitas yang telah disediakan tersebut tidak selalu dianggap memuaskan, terdapat juga responden yang merasa kurang puas.Ketidakpuasan itu disebabkan oleh kursi pemeriksaan gigi yang dirasa kurang nyaman, dan juga beberapa responden yang mengalami kesulitan saat menemukan Poliklinik Gigi karena letaknya berada di lantai dua gedung puskesmas dan ukuran papan penunjuk yang kecil. 
$==================================$

Received: 22 April 2020 :: Accepted: 28 April 2020 :: Published: 30 April 2020

\section{METODE}

Jenis penelitian ini yang digunakan adalah survei analitik dengan desain cross sectional. Penelitian dilakukan pada pasien Puskesmas Amplas Kota Medan, Sumatera Utara, jumlah sampel adalah 100 orang yang telah memenuhi kriteria inklusi dan eksklusi. diharapkan tidak mengalami cacat, kelainan fisik kongenital dan maloklusi berat.

Adapun metode anlisis data menggunakan melalui proses proses pengolahan data dengan tahapanUnivariat dan Bivariat.

\section{HASIL}

Berdasarkan penelitian yang sudah dilakukan, diperoleh gambaran karakteristik responden yang meliputi umur dan jenis kelamin.

Distribusi frekuensi responden berdasarkan karakteristik menunjukkan bahwa sebagian besar responden non JKN berusia antara 3039 tahun sedangkan responden JKN mayoritas berusia 40-49 tahun (39.6\%). Dilihat dari jenis kelaminnya, baik pasien non JKN maupun JKN mayoritas adalah perempuan yaitu masing-masing $53,3 \%$ dan $80 \%$.

Tabel 3.1 Distribusi karakteristik responden

\begin{tabular}{lccccc}
\hline Karakteristik & \multicolumn{2}{c}{ Non JKN } & \multicolumn{2}{c}{ JKN } & Total \\
\hline Umur & N & $\%$ & N & $\%$ & \\
$20-29$ & 15 & $31.9 \%$ & 10 & $18.8 \%$ & 25 \\
$30-39$ & 22 & $46.8 \%$ & 15 & $28.3 \%$ & 37 \\
$40-49$ & 7 & $16.6 \%$ & 21 & $39.6 \%$ & 28 \\
$50-59$ & 3 & $6.38 \%$ & 7 & $13.2 \%$ & 10 \\
\hline JenisKelamin & 35 & $46.6 \%$ & 15 & $20 \%$ & 50 \\
Laki-laki & 40 & $53.3 \%$ & 60 & $80 \%$ & 50 \\
Perempuan & & & & & \\
\hline
\end{tabular}

Tingkat kepuasan dalam penelitian ini diukur melalui dimensi pelayanan kesehatan yang meliputi; bukti fisik, kehandalan, daya tanggap, jaminan dan empaty.Berdasarkan analisis deskriptif, tingkat kepuasan responden dapat diuraikan pada tabel dibawah.

Berdasarkan tabel dibawah ini dapat diketahui bahwa responden non JKN dan JKN terhadap poliklinik di Faskes tingkat I mayoritas memiliki

tingkat kepuasan yang tinggi (42.6\%) pada pasien JKN.Sedangkan mayoritas responden pasien non JKN mayoritas memiliki tingkat kepuasan yang sedang (38.8\%).

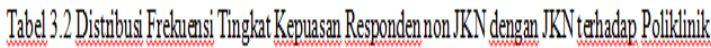

\section{di Faskes Iinglat I}

\begin{tabular}{|c|c|c|c|c|c|}
\hline \multirow{2}{*}{ Timgkat Kepuassan } & \multicolumn{2}{|c|}{ Non JKN } & \multicolumn{2}{|c|}{ JKN } & \\
\hline & N & $\%$ & $N$ & $\%$ & Ilolat \\
\hline Tingg & 5 & $27.7 \%$ & 35 & $42.6 \%$ & 40 \\
\hline Sedang & 7 & $38.8 \%$ & 27 & $32.9 \%$ & 34 \\
\hline Rendah & 6 & $333.3 \%$ & 20 & $24.3 \%$ & 26 \\
\hline
\end{tabular}

Berdasarkan dimensi pengukurannya, tingkat kepuasan pasien non JKN dan JKN pada bagian pendaftaran Faskes Tingkat 1 di Puskesmas Amplas Kota Medan dapat diuraikan sebagai berikut:

Diketahui bahwa pada setiap aspek, mayoritas responden memiliki tingkat kepuasan sedang. Pada aspek kehandalan $55.5 \%$ non JKN menyatakan kepuasan pelayanan poliklinik di Faskes tingkat I Puskesmas Amplas Kota Medan disusul dengan aspek pada ketanggapan $27.7 \%$,padaaspekjaminan $33.3 \%$ danaspeksikap penampilan $38.8 \%$ sertapadaaspeksikappeduli $22.2 \%$.

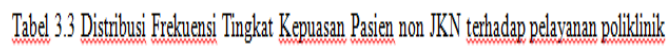

\section{gigi di Faskes Tinghat I}

\begin{tabular}{|c|c|c|c|c|c|c|c|c|c|}
\hline \multirow{3}{*}{$\begin{array}{c}\text { Aspels: } \\
\text { appedKRpuasin }\end{array}$} & \multicolumn{6}{|c|}{ Kepuasempasien Nou JKN } & \multicolumn{3}{|c|}{ Nilai } \\
\hline & \multicolumn{2}{|c|}{ Timggi } & \multicolumn{2}{|c|}{ Sedang } & \multicolumn{2}{|c|}{ Rendah } & \multirow[t]{2}{*}{ Total } & \multirow{2}{*}{$\begin{array}{l}\text { Rata- } \\
\text { frata }\end{array}$} & \multirow[t]{2}{*}{ Kategeri } \\
\hline & N & $\%$ & $N$ & $\%$ &. & $\%$ & & & \\
\hline Kehandalan & 3 & $16.6 \%$ & 10 & $21.7 \%$ & 5 & $27.7 \%$ & 18 & 125.5 & Sedang \\
\hline Dava Tangar & 7 & $38.8 \%$ & j & $27.7 \%$ & 6 & $33.3 \%$ & 18 & 120.2 & Sedang \\
\hline Jamman & 6 & $33.3 \%$ & 6 & $40.3 \%$ & 6 & $33.3 \%$ & 18 & 122.7 & Sedang \\
\hline Sikag dan & 10 & $55.5 \%$ & 1 & $38.8 \%$ & 1 & $5.5 \%$ & 18 & 120.5 & Selange \\
\hline Sikan Pedulli & 9 & $50 \%$ & 4 & $22.2 \%$ & j & $27.7 \%$ & 18 & 119.5 & Sedang \\
\hline
\end{tabular}

Berdasarkan tabel dibawah menunjukkan bahwa pada setiap aspek pengukuran kepuasan, mayoritas pasien JKN memiliki tingkat kepuasan yang tinggi.Pada aspek kehandalan misalnya, 45.1\% pasien JKN menyatakan kepuasan

Tabel4. Distribusi Frekuensi Tingkat Kepuasan Pasien JKN terhadap pelayanan poliklinik gigi di Faskes Tingkat I

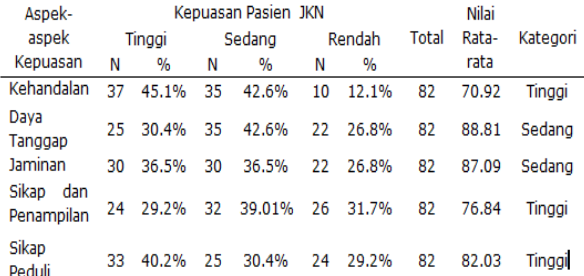


yang tinggi begitu juga pada aspek ketanggapan yaitu sebesar 30.4\%, pada aspek jaminan sebesar $36.5 \%$, aspek sikap dan penampilan $29.2 \%$ dan $40.2 \%$ pada aspek sikap peduli.

\section{Analisis Data}

Analisa bivariat dilakukan untuk mengetahui ada tidaknya perbedaan bermakna antara tingkat kepuasan pasien pengguna non JKN dengan pasien JKN yang memanfaatkan layanan kesehatan di Puskesmas Amplas Kota Medan. Analisis penelitian ini berdasar pada uji komparatif dengan $u j i$ hipotesis mengacu pada rumus Mann-WhitneyWilcoxon (MWW) atau lebih dikenal dengan uji $U$.

Berdasarkan aspek-aspek pengukurannya dapat diketahui dari tabel dibawah bahwa Aspek Kehandalan mempunyai nilai apabila $\rho \quad \operatorname{sig}(2$-tailed) $<0,05$. Dengan demikian berarti $\mathrm{HO}$ ditolak yang artinya ada perbedaan tingkat kepuasan yang signifikan pada aspek kehandalan antara pasien non JKN dan JKN.

\begin{tabular}{|c|c|c|c|c|c|}
\hline $\begin{array}{c}\text { Dimensi } \\
\text { Kepusssn }\end{array}$ & $\begin{array}{c}\text { Nilai } \\
\text { Mean } \\
\text { Rank } \\
\text { Pasien } \\
\text { Non JKN }\end{array}$ & $\begin{array}{c}\text { Nilei } \\
\text { Rentan } \\
9\end{array}$ & $\begin{array}{l}\text { Nilai Mesn } \\
\text { Rank } \\
\text { Pasien JKN }\end{array}$ & $\underset{U}{N i l s i}$ & $\begin{array}{c}\text { P sig } \\
(2- \\
\text { talied })\end{array}$ \\
\hline Kehandalan & 125.5 & 53.16 & 79.92 & $\begin{array}{c}2330 . \\
4\end{array}$ & 0.000 \\
\hline Tanggap & 120.2 & 31.26 & 88.81 & 3397 & 0.000 \\
\hline Jaminan & 122.7 & 35.5 & 87.09 & 5 & 0.001 \\
\hline $\begin{array}{l}\text { Siksp dan } \\
\text { Pensmpilan }\end{array}$ & 120.5 & 60.68 & 76.84 & 19645 & 0.000 \\
\hline Peduli & 119.5 & 47.96 & 82.03 & 2584 & 0.000 \\
\hline Total & 128.65 & 45.71 & 82.94 & I & \\
\hline
\end{tabular}

\section{Pembahasan}

Tujuan penelitian ini adalah untuk mengetahui tingkat kepuasan pasien non JKN dengan JKN terhadap pelayanan poliklinik gigi di Faskes I pada Puskesmas Amplas Kota Medan. Penelitian ini dilakukan dengan cara mewawancarai langsung kepada sampel menggunakan kuesioner. Adapun hambatan adalah sulitnya mengumpulkan sampel, sehingga penelitian ini harus dilakukan dengan cara menemui responden secara langsung.

Metode cross sectional yang digunakan dalam penelitian ini digunakan dalam melihat tingkat kepuasan pasien non JKN dengan JKN pada poliklinik gigi di faskes tingkat I. Hasil wawancara, responden merasa cukup baik dalam melaksanakan aktivitas seharisehari. Hal ini juga dilakukan oleh Zarra tahun 2016 yang ada perbedaan tingkat kepusan pasien BPJSdengan tingkat kepuasan pasien non BPJSdi RSP AU dr. S. Hardjolukito.

Berdasarkan jenis kelamin, hasil penelitian diperoleh sampel, perempuan lebih banyak dibandingkan laki-laki.Hasil penelitian ini sejalan dengan beberapa penelitian sebelumnya bahwa tingkat kepuasan pasien non JKN dan JKN dengan tingkat kepuasan pasien poliklinik gigi didominasi oleh perempuan.Keadaan tersebut kemungkinan disebabkan kepedulian perempuan terhadap kesehatan gigi dan mulut serta penampilan lebih tinggi dibandingkan dengan laki-laki.Selain itu juga, adanya fase menopause pada perempuan yang dapat mempengaruhi kesehatan gigi dan mulutnya, sehingga menyebabkan menurunkan kemampuan sekresi saliva.

Ditinjau dari lama dimensi kepuasan dapat dilihat bahwa Aspek Ketanggapan terdapatnilai $\boldsymbol{\rho}$ sig (2tailed) pada aspek ketanggapan adalah sebesar 0,000 $(<0,05)$. Dengan demikian berarti $\mathrm{HO}$ ditolak yang artinya ada perbedaan tingkat kepuasan yang signifikan pada aspek ketanggapan antara pasien non JKNdan JKN. Pada aspek jaminan nilai $\boldsymbol{\rho}$ sig (2-tailed) pada aspek 
jaminan adalah sebesar 0,000 $(<0,05)$. Dengan demikian berarti Dengan demikian berarti $\mathrm{HO}$ ditolak yang artinya ada perbedaan tingkat kepuasan yang signifikan pada aspek jaminan antara pasien non JKN dan JKN. Aspek sikap dan penampilan nilai $\mathbf{\rho}$ sig (2-tailed) pada aspek sikap dan penampilan adalah sebesar $0,000(<0,05)$. Dengan demikian berarti $\mathrm{HO}$ ditolak yang artinya ada perbedaan tingkat kepuasan yang signifikan pada aspek sikap dan penampilan antara pasien non JKN dan JKN. Aspek sikap peduli nilai $\boldsymbol{\rho}$ sig (2-tailed) pada aspek sikap peduli adalah sebesar $0,000 \quad(<0,05)$. Dengan demikian berarti $\mathrm{HO}$ ditolak yang artinya ada perbedaan tingkat kepuasan yang signifikan pada aspek sikap peduli antara pasien non JKN dan JKN.

Uji U. (Mann Withney) menunjukkan hasil nilai sig $p<0,05$ maka kesimpulannya $\mathrm{HO}$ ditolak, artinya bahwa ada perbedaan tingkat kepusan pasien non JKN dengan tingkat kepuasan pasien JKN di faskes tingkat I pada Puskesmas Amplas Kota Medan.

\section{Kesimpulan}

Mayoritas pasien non JKN di Puskesmas Amplas Kota Medan 30-39 tahun $(46,8 \%)$, berjenis kelamin perempuan $(53,3 \%)$. Demikian juga pada pasien JKN secara umum memiliki karakteristik yang tidak jauh berbeda, yaitu sebagian besar berumur 40-49 tahun $(39.6 \%)$, berjenis kelamin perempuan $(80 \%)$.

Pasien JKN sebagian besar $(42,6 \%)$ menyatakan kepuasan yang tinggi terhadap pelayanan poliklinik gigi faskes tingkat I di Puskesmas Amplas Kota Medan dengan nilai tertinggi pada aspek Kehandalan $(45,1 \%)$ sedangkan pasien non JKN sebagian menyatakan tingkat kepuasannya sedang (38.8\%) dengan nilai tertinggi ada pada aspek jaminan $(40,3 \%)$.

Berdasarkan uji Mann-Whiteney $U$ Test, diperoleh nilai $p=0,000$ sehingga $\mathrm{p}<0,05$ maka $\mathrm{H}_{\mathrm{o}}$ ditolak dan dapat disimpulkan ada perbedaan tingkat kepuasan pelayanan antara pasien non JKN dan JKN poliklinik gigi Faskes Tingkat I di Puskesmas Amplas Kota Medan.

\section{Daftar Pustaka}

Dewanto, I., \& Lestari, N. I. (2014). Panduan Pelaksanaan Pelayanan Kedokteran Gigi dalam system jaminan kesehatan Nasional. Jakarta Timur: Pengurus esar Persatuan Dokter Gigi Indonesia

Jalimun, Y. P., Widjanarko, B., \& Peitojo, H. (2014). Kepuasan Pasien di Balai Pengobatan Gigi (BPG) Puskesmas Kahuripan Kota Tasikmalaya.

Kementerian Kesehatan Republik Indonesia, Lembaga Penelitian dan Pengembangan Kesehatan Nasional, (2018). Laporan Hasil Riset Kesehatan Dasar Nasional (RISKESDAS); 2018. Republik Indonesia: Kementerian Kesehatan; 2018: 100-103.

Menteri Kesehatan Republik Indonesia.(2014). Peraturan Menteri Kesehatan No. 28. Jakarta.

Notoatmojo.(2014). Metodologi Penelitian Kesehatan. Jakarta: RhinekaCipta.

Sugiyono, (2016).Metode Penelitian Pendidikan-Pendekatan

Kuantitatif, Kualitatif, dan $R \& D$ (Cetakan ke 7), Bandung : Penerbit Alfabeta.

Taher, A.

(2013).Kesiapan

Implementasi

JKN dan Peran Fakultas

Kedokteran 
Dalam Penyediaan Dokter Layanan

Primer. Materi Seminar Kesiapan Implementasi JKN Di Provinsi Jawa

Barat Bandung, 21 Desember 2013

Direktorat Jenderal Bina Upaya Kesehatan, Kementerian Kesehatan

RI. 